\title{
On the Negative Impact of Time Zone Differences on International Tourism
}

Mathias Czaika ${ }^{1}$ and Eric Neumayer ${ }^{2}$

${ }^{1}$ Department for Migration \& Globalisation, Danube University Krems, Austria mathias.czaika@donau-uni.ac.at

2 Department of Geography \& Environment, London School of Economics and Political Science (LSE), London, UK, e.neumayer@Ise.ac.uk

\section{ABSTRACT}

This research note reports novel results on the negative effect of time zone differences on international tourism in a global sample of countries over the period 1995 to 2013. A gravity-type model, which has become standard in international tourism demand, is estimated with PseudoPoisson maximum likelihood, controlling for geographical distance and other potential confounders at the dyadic level in addition to origin-year and destination-year fixed effects. The effect of time zone differences is found to be substantively strong and approximately (log-)linear across the various hours of time zone difference, with an average negative effect of about 11.6 per cent per hour of time difference.

Key words: tourism demand; international tourism; time difference; distance; economic geography; gravity model

Data availability statement: The data that support the findings of this study are available from the corresponding author, EN, upon reasonable request. 


\section{Introduction}

In contrast to geographical or physical distance, the effect that time zone differences exert as barriers to international economic activity has only recently been analysed; see, for example, Stein and Daude (2007) on foreign direct investment and Egger and Larch (2013) as well as Christen (2017) on international trade. As these studies suggest, economic activity is negatively affected by time zone differences because of two main reasons: the reduction of overlap in normal business hours and the negative impact on the well-being of individuals that travelling across time zones can have. The latter stems from the temporary misalignment between the circadian clock, located in the suprachiasmatic nucleus of the hypothalamus of people, and local time - a phenomenon colloquially described as 'jet lag', which typically results in sleeplessness during the night and tiredness during the day (Sack 2010). It takes a few days to adjust, only to face the same issues again on the return journey. The reduction in overlap in normal business hours that comes with time zone differences is likely to matter less for international tourism than for international trade and foreign direct investment. Yet, jet lag matters more since contrary to trade and investment this economic activity by definition requires individuals to cross national borders.

This is the first research to analyse the effect of time zone differences on international tourist travel over and beyond the effect of geographical distance. The hypothesis is tested that time zones negatively impact on international tourist travel, allowing for non-linear effects, in a global sample of country dyads over the period 1995 to 2013. Employing the so-called gravity model, which has become the standard in international tourism demand research (see, for example, Morley, Rosselló and Santana-Gallego 2014; Santeramo and Morelli 2016; Khoshnevis Yazdi and Khanalizadeh 2017), the findings of the research suggest that international tourist arrivals are reduced by on average about 11.6 per cent per hour time difference. 


\section{Methods}

The estimations cover a global sample over the period 1995 to 2013 for which UNWTO (2015) provides dyadic (country-pair) data on inbound tourism by country of origin, measured by total annual arrivals (and overnight stays). The effect of time zone differences is estimated on international tourism from origin country $i$ to destination country $j$ in year $t$ in a gravity-type model with a pseudo-Poisson maximum likelihood estimator, which has become the standard estimation approach for this type of model (Silva and Tenreyro 2006). The inclusion of origin-year and destination-year fixed effects obliterate the need to control for any confounding factors that vary over time only at the level of the origin or the destination country. This is the most stringent specification that panel data affords given the central variable of interest is essentially time-invariant at the country dyad level.

The central explanatory variable is the time difference between two countries in hours, as provided by Centre d'Etudes Prospectives et d'Informations Internationales (CEPII) (Mayer and Zignago 2011). For countries such as Russia, Canada, and the United States, which stretch over more than one time zone, the respective time zone is generated via the mean of all its time zones (cf. Mayer and Zignago 2011). Time zone differences should in principle be orthogonal to North-South distance (differences in latitude) but strongly correlated with East-West distance (differences in longitude). Yet, countries have some wriggle room: they tend to keep the time zone within their national boundary the same unless their East-West extension is too large. China insists on one single time zone throughout despite large East-West extension, with the consequence that some parts of this country are well above two hours off the solar time given their longitudinal position. Countries might also adopt a time zone that is inconsistent with their longitudinal coordinate in order to share a time zone with an important trading or political partner. As a consequence, not a single time zone follows vertical longitudinal lines on a world map, as they would if the time zone followed solar time, but all of them exhibit bulges on either side. 
Other variables at the dyadic level that affect tourist flows are controlled for, namely if country $j$ imposes a visa requirement on nationals from country $i$ in year $t$. Comprehensive visa data are taken from the DEMIG VISA database (Czaika et al. 2018). We further include the size of the migrant stock of country $i$ in country $j$ (sourced from World Bank 2011), as well as contiguity (i.e. sharing a land border), colonial history between the two countries, and, most importantly, measures of (population-weighted) bilateral distances (in kilometres) for country pair ij, with all these data taken from the Geodist dataset as provided by CEPII (Mayer and Zignago 2011). Results are practically identical if the total volume of trade between a country-pair as a proxy for close economic relations is additionally included (data from the Center for International Data at UC Davis; results not shown). In some of the estimations distance is disaggregated into longitudinal and latitudinal distance components, following the decomposition suggested by Stein and Daude (2017). Note that a very small number of observations are lost since these disaggregated variables could not be computed for all dyads for which aggregate distance information is available. The construction of longitudinal and latitudinal distance follows the following formula (cf. Stein and Daude 2007):

(1) Latitude_distance $_{i j}=12742 \cdot \arctan 2(\sqrt{A}, \sqrt{1-A})$ with

$$
A=\sin \left(\left|l a t_{i}-\operatorname{lat}_{j}\right| \cdot \frac{\pi}{90}\right)^{2} \cdot \cos \left(\operatorname{lat}_{j} \cdot \frac{\pi}{90}\right) \cdot \sin \left(\left|\operatorname{lon}_{i}-\operatorname{lon}_{j}\right| \cdot \frac{\pi}{90}\right)^{2}
$$

(2) Longitude_distance $e_{i j}=\frac{D+E}{2}$ with

$$
\begin{aligned}
& D=12742 \cdot \arctan 2(\sqrt{B}, \sqrt{1-B}) \text { and } \\
& E=12742 \cdot \arctan 2(\sqrt{C}, \sqrt{1-C}) \text { and } \\
& B=\sin \left(\left|\operatorname{lat}_{i}-\operatorname{lat}_{i}\right| \cdot \frac{\pi}{90}\right)^{2}+\cos \left(\text { lat }_{i} \cdot \frac{\pi}{180}\right)^{2} \cdot \sin \left(\left|\operatorname{lon}_{j}-\operatorname{lon}_{i}\right| \cdot \frac{\pi}{90}\right)^{2} \text { and } \\
& C=\sin \left(\mid \operatorname{lat}_{j}-\text { lat }_{j} \mid \cdot \frac{\pi}{90}\right)^{2}+\cos \left(\text { lat }_{j} \cdot \frac{\pi}{180}\right)^{2} \cdot \sin \left(\left|\operatorname{lon}_{j}-\operatorname{lon}_{i}\right| \cdot \frac{\pi}{90}\right)^{2} .
\end{aligned}
$$

Latitudinal (North-South) distance is essentially uncorrelated with time zone difference at $\rho=0.12$, while time zone difference is strongly correlated at $\rho=0.78$ with longitudinal (East-West) distance.

\section{Results}

Table 1 presents the estimation results. Model 1 is a standard gravity-type model without the time difference variable, which enters in model 2 . The coefficients of the set of control variables show the 
expected signs. International tourism decreases with increasing distance, increases if the two countries are geographically contiguous, increases with a higher stock of migrants from the origin country living in the destination country and is reduced by travellers from the origin country requiring a visa to enter the destination country. We do not find, however, that colonial history has a statistically significant effect. For the central variable of interest, a statistically significant negative effect of time zone differences on bilateral travel is found. Taking the relevant coefficient of -0.123 from model 2, in substantive terms this semi-elasticity implies an average effect of about 11.6 percent less international travel per hour time difference, which is computed as $\Delta \mathrm{Y}=(\exp (-0.123)$ $1)^{*} \Delta \mathrm{X} * 100 \%$

Model 3 allows for a non-linear effect of time zone differences by adding its second-order polynomial. The second order polynomial term in model 3 is only marginally statistically significant at the $10 \%$ level. Models 4 to 6 repeat models 1 to 3 but replacing Euclidean ('as the crow flies') distance by its respective latitude and longitude distance. Results indicate that longitudinal distance matters statistically and economically significantly more than latitudinal distance. More importantly, the results across the various models suggest a robust and statistically significant semi-elasticity between bilateral travel and of time zone difference, independently of whether distance is measured by aggregate geographical distance or by its disaggregation into latitude and longitude distance. That the coefficient of the second order polynomial term in model 6 is statistically insignificant corroborates the inference that the effect of time zone differences is approximately linear. 
Table 1 Pseudo-Poisson Maximum Likelihood estimation results

\begin{tabular}{|c|c|c|c|c|c|c|}
\hline & $\mathrm{m} 1$ & $\mathrm{~m} 2$ & $\mathrm{~m} 3$ & $\mathrm{~m} 4$ & $\mathrm{~m} 5$ & $\mathrm{~m} 6$ \\
\hline Distance (In) & $\begin{array}{c}-0.845^{* * *} \\
(0.0794)\end{array}$ & $\begin{array}{c}-0.564 * * * \\
(0.0989)\end{array}$ & $\begin{array}{c}-0.555^{* * *} \\
(0.0995)\end{array}$ & & & \\
\hline Time difference & & $\begin{array}{c}-0.123^{* * *} \\
(0.0182)\end{array}$ & $\begin{array}{c}-0.176 * * * \\
(0.0405)\end{array}$ & & $\begin{array}{c}-0.128 * * * \\
(0.0128)\end{array}$ & $\begin{array}{c}-0.172 * * * \\
(0.0330)\end{array}$ \\
\hline Time difference (sq) & & & $\begin{array}{l}0.00579 * \\
(0.00331)\end{array}$ & & & $\begin{array}{c}0.00483 \\
(0.00306)\end{array}$ \\
\hline Latitude distance (In) & & & & $\begin{array}{l}-0.0219 \\
(0.0275)\end{array}$ & $\begin{array}{c}-0.0347 \\
(0.0275)\end{array}$ & $\begin{array}{l}-0.0353 \\
(0.0274)\end{array}$ \\
\hline Longitude distance (In) & & & & $\begin{array}{c}-0.481 * * * \\
(0.0274)\end{array}$ & $\begin{array}{c}-0.317^{* * *} \\
(0.0341)\end{array}$ & $\begin{array}{c}-0.312 * * * \\
(0.0343)\end{array}$ \\
\hline Visa restriction & $\begin{array}{c}-0.455 * * * \\
(0.0781)\end{array}$ & $\begin{array}{c}-0.469 * * * \\
(0.0787)\end{array}$ & $\begin{array}{c}-0.471 * * * \\
(0.0793)\end{array}$ & $\begin{array}{c}-0.545 * * * \\
(0.0763)\end{array}$ & $\begin{array}{c}-0.535^{* * *} \\
(0.0770)\end{array}$ & $\begin{array}{c}-0.536 * * * \\
(0.0775)\end{array}$ \\
\hline Migrant stock (In) & $\begin{array}{c}0.231^{* * *} \\
(0.0178)\end{array}$ & $\begin{array}{c}0.232 * * * \\
(0.0170)\end{array}$ & $\begin{array}{c}0.230 * * * \\
(0.0169)\end{array}$ & $\begin{array}{c}0.275^{* * *} \\
(0.0168)\end{array}$ & $\begin{array}{c}0.256 * * * \\
(0.0156)\end{array}$ & $\begin{array}{c}0.254^{* * *} \\
(0.0156)\end{array}$ \\
\hline Colony & $\begin{array}{l}0.0257 \\
(0.110)\end{array}$ & $\begin{array}{c}0.116 \\
(0.105)\end{array}$ & $\begin{array}{c}0.129 \\
(0.105)\end{array}$ & $\begin{array}{l}-0.0530 \\
(0.0988)\end{array}$ & $\begin{array}{c}0.0719 \\
(0.0985)\end{array}$ & $\begin{array}{c}0.0832 \\
(0.0993)\end{array}$ \\
\hline Contiguity & $\begin{array}{c}1.093 * * * \\
(0.141)\end{array}$ & $\begin{array}{c}1.081^{* * *} \\
(0.123)\end{array}$ & $\begin{array}{c}1.073^{* * *} \\
(0.122)\end{array}$ & $\begin{array}{c}1.203^{* * *} \\
(0.100)\end{array}$ & $\begin{array}{c}1.146 * * * \\
(0.0992)\end{array}$ & $\begin{array}{c}1.139 * * * \\
(0.1000)\end{array}$ \\
\hline Observations & 185,418 & 185,418 & 185,418 & 184,786 & 184,786 & 184,786 \\
\hline R-squared & 0.900 & 0.914 & 0.915 & 0.930 & 0.932 & 0.932 \\
\hline
\end{tabular}

Note: Dependent variable is international tourist arrivals. Standard errors clustered at dyad level in parentheses.

$* * * p<0.01, * * p<0.05, * p<0.1$

To explore potential non-linearity in the effect of time zone differences more flexibly, instead of estimating the effect in a model with a second-order polynomial term, separate effects for each hour of time zone difference have been estimated, employing aggregate geographical distance as the distance control variable. Figure 1 displays the point estimates and 95\% confidence intervals for each of the dummy variables for 1 to 11 hour time difference, respectively. Figure 1 suggests that the (log-)linearity assumption seems a reasonable approximation for the effect across time zone differences though the effects will typically be only statistically significantly different from each other across several hours of time zone difference rather than from one hour to the next.

In terms of substantive effect sizes, dummy variable point estimates give the total effect of the respective time difference according to the formula (exp(beta) - 1 )*100 \%. So, for example, for a time difference of 8 hours, the effect is $\exp (-2.1)-1$, or approximately $88 \%$. Relative to the travel volume between countries with no time difference, it is estimated that a one hour time difference 
reduces international tourism travel by about 41 percent $(95 \%-\mathrm{Cl}: 31-50$ percent), while a difference of 4 hours reduces international tourism by about 76 percent (95\%-Cl: $69-82$ percent). A time zone difference of 8 hours reduces international tourism by about 88 percent (95\%-Cl: $83-91$ percent). After 8 hours, additional hours of time difference are not statistically significantly different from the effect at 8 hours. One possible interpretation is that after the 8 hours threshold of time difference additional hours no longer make much additional difference since the circadian clock is already completely out of tune with the time in the destination country. Note that the effect of reducing international tourism by about 88 percent at 8 hours of time difference is essentially consistent with the result from table 1 employing a linear time difference variable, in which the average effect of international tourism reduction was found to be 11.6 percent per hour time difference.

Figure 1 Effect on bilateral travel by time zone difference between origin and destination

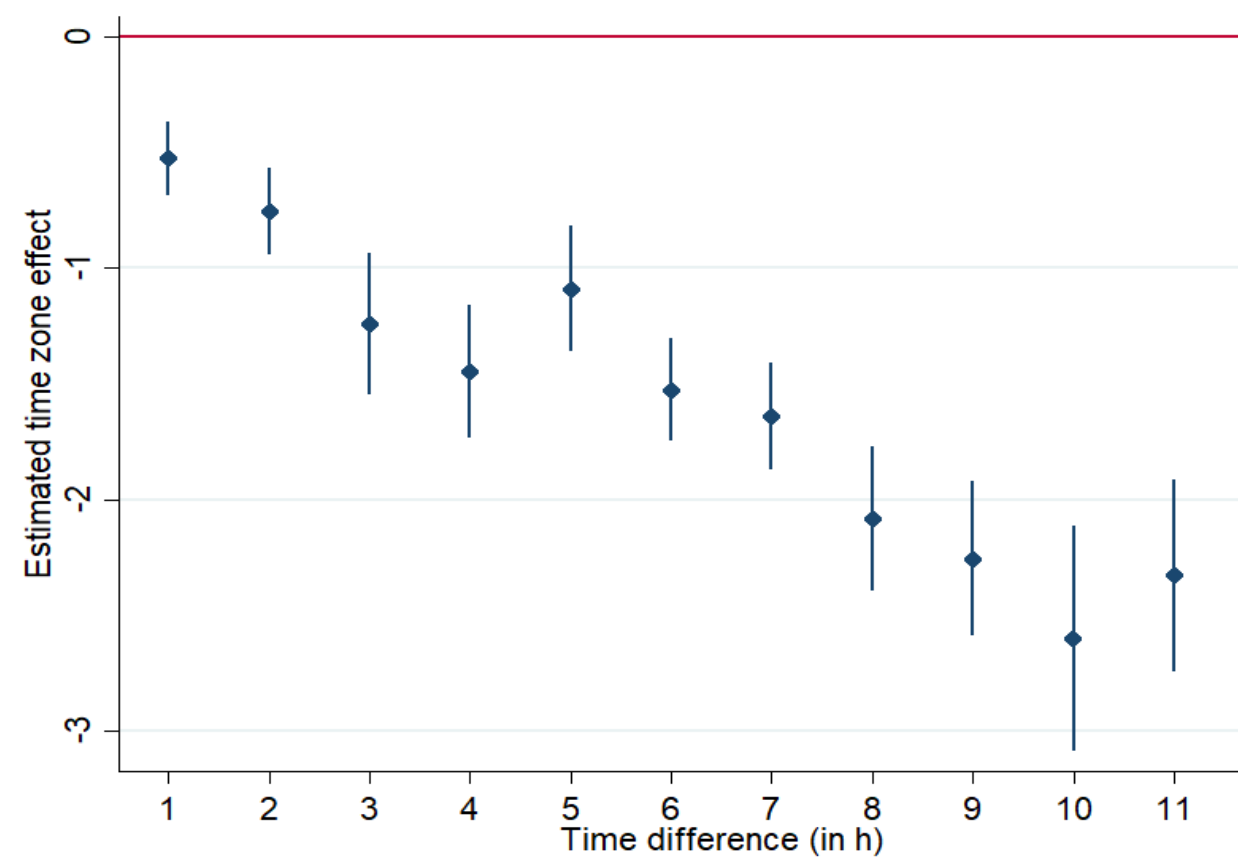

\section{Conclusion}

This analysis has demonstrated that time zone differences deter international tourist flows in substantively important ways, just like other studies have demonstrated negative effects on 
international trade and foreign direct investment. This study therefore provides another piece of evidence for the importance of space and location in shaping international economic activity. Time zone differences impose an important constraint on the extent to which tourism destinations can convert latent demand for tourism from source countries into actual arrivals if these source countries are located in different time zones.

\section{Disclosure statement}

No potential conflict of interest was reported by the authors.

\section{Funding}

No specific funding supported this work.

\section{References}

Christen, E. (2017) Time zones matter: The impact of distance and time zones on services trade. The World Economy, 40(3), pp.612-631.

Czaika, M., de Haas, H. and Villares-Varela, M. (2018) The global evolution of travel visa regimes. Population and Development Review, 44(3), pp. 589-622.

Egger, P.H. and Larch, M. (2013) Time zone differences as trade barriers. Economics Letters, 119(2), pp.172-175.

Khoshnevis Yazdi, S. and Khanalizadeh, B. (2017) Tourism demand: a panel data approach. Current Issues in Tourism, 20(8), pp.787-800.

Mayer, T. and Zignago, S. (2011) Notes on CEPII's distances measures: the GeoDist Database, CEPII Working Paper 2011-25 
Morley, C., Rosselló, J. and Santana-Gallego, M. (2014) Gravity models for tourism demand: theory and use. Annals of Tourism Research, 48, pp.1-10.

Sack, R.L., (2010) Jet lag. New England Journal of Medicine, 362(5), pp.440-447.

Santeramo, F.G. and Morelli, M. (2016) Modelling tourism flows through gravity models: a quantile regression approach. Current Issues in Tourism, 19(11), pp.1077-1083.

Silva, J.S. and Tenreyro, S. (2006) The log of gravity. The Review of Economics and Statistics, 88(4), pp.641-658.

Stein, E. and Daude, C. (2007) Longitude matters: Time zones and the location of foreign direct investment. Journal of International Economics, 71(1), pp.96-112.

UNWTO (2015) Statistical information on CD-Rom. Madrid: World Tourism Organization. World Bank (2011) Global Bilateral Migrant Stock Database, Washington, DC: World Bank. WTTC (2017) The economic impact of travel \& tourism. World Travel \& Tourism Council. 